\title{
Curriculum Teaching Reform of Advanced Mathematics in Application-Oriented Universities-with Nanchang Institute of Science \& Technology as an Example
}

\author{
Xiongyun Xuan
}

The foundation Department ,Nanchang Institute of Science \& technology, Nanchang 330108,China xyx38@126.coml

\section{Keywords: Advanced mathematics; Mathematics teaching reform; Application-oriented} universities

\begin{abstract}
This paper, among the first, analyzes the curriculum teaching reform of Advanced Mathematics in application-oriented universities. Based on its actual situation, this paper establishes a new mathematical knowledge module to better serve for the follow-up professional courses, thus improving the quality of Applied Mathematics teaching in colleges and universities. Advanced Mathematics; mathematics teaching reform; application-oriented universities This template explains and demonstrates how to prepare your camera-ready paper for Trans Tech Publications. The best is to read these instructions and follow the outline of this text.
\end{abstract}

\section{Applied Undergraduate Math Teaching Problems}

It is urgent to guide the transformation of some local undergraduate colleges and universities toward application model and demand the deepening of personnel training programs and curriculum reform, with higher education being seriously homogeneity-inclined, application-oriented interdisciplinary and innovative talents of production and service industry in short supply, and personnel training structure and quality incompatible with the requirements of economic restructuring and industrial upgrading,.

Presently, Advanced Mathematics course education in most colleges and universities is 'subject-based', which shows itself in the teaching in 3 ways--- emphasizing the independent importance of Mathematics; emphasizing the logic and integrity of mathematical knowledge; and emphasizing the knowledge system of Mathematics;

'Subject-based education' has not adapted to the current requirements of applied universities. Hence the demand for transformation to 'ability-based education' which requires of Advanced Mathematics course less emphasis on the systematicity and intrinsic logic of subject knowledge; a supply of major-oriented mathmatical knowledge; and greater emphasis on combination of theory with practice to solve practical problems.

Meanwhile, current Mathematics course teaching presents various problems---poor basis, uneven levels, insufficient hours and unsuitable teaching material (most designed for research-oriented institutions that differ from application-oriented ones ). These problems require that application-oriented colleges and universities direct their Advanced Mathematics course reform toward better serving the goal of talent training and improving students' ability to solve practical problems. To achieve these purposes, colleges and universities should first strengthen the connection between curriculum content and major knowledge and then construct new teaching modes involving various teaching methods. Hence our efforts to carry out teaching reform in Advanced Mathematics course.

\section{Research on Modular Teaching Mode of Advanced Mathematics Course in Application-Oriented Universities}

Traditional Advanced Mathematics course have strong theoretical, lack of applying. Emphasis on the integrity of knowledge, ignoring the applicability of knowledge. Thus, it is accorded the requirements of 
talents training in applied colleges and universities, combined with the actual situation of students in our university, clear objectives, clarify ideas, innovate and put forward a teaching type of modular .

\section{Clear Course Positioning}

According to the newly formulated "Requirements for Teaching Basic Courses in Mathematics for Science \& Engineering Undergraduate Majors", this mode proposes an 'application-oriented,' 'imperative-adequate-moderate' teaching philosophy and a 'basicality-serviceability-applicability-integrated' course positioning.

This new positioning emphasizes the importance of Advanced Mathematics as a foundation for follow-up major study, and students' ability to apply mathematical knowledge in practical problems.

\section{Starting Points of Mathematics Course Teaching}

Advanced Mathematics course teaching, based on the starting point of 'all for students; all for major development', should observe the laws of education and teaching, enhancing students' ability to learn and apply knowledge.

\section{Understanding Students' Needs in Mathematics Learning}

Based on the course positioning and starting point, three different levels of needs are proposed:

The need for basic Advanced Mathematics knowledge required for subsequent major study.

The need for higher-level Advanced Mathematics knowledge required for further development in the future.

The need for ability to analyze and solve problems and cultivate innovative thinking.

\section{Accurate Module System in Place}

According to the positioning and starting point of mathematics curriculum in application-oriented colleges and universities, four levels of mathematical knowledge modules are established to meet the actual needs of students.

\section{Module One: Preliminary Knowledge Module}

This module aims at students who have weak mathematical knowledge foundation and lack confidence in math study. In content, it reviews part of Elementary Mathematics knowledge, serving as a link between elementary study and advanced study.

\section{Module Two: Basic Knowledge Module}

This module aims at students of all majors. In content, it meets the basic needs of all majors and professions for advanced mathematical knowledge.

\section{Module Three: Advanced Knowledge Module}

This module aims at specific majors. In content, it is an extension of basic knowledge module and meets the higher-level needs of specific majors and professions for mathematical knowledge .

\section{Module Four: Applied Knowledge Module}

This module aims at the application of mathematical knowledge in the context of various majors. In content, it is an enhancement of the basic and advanced knowledge module.

\section{Measures of Advanced Mathematics Curriculum Reform in Application-Oriented Colleges and Universities}

A series of reforms have been conducted based on the curriculum positioning and students' needs. The measures are as follows.

\section{Making Questionnaires}

In the survey, the teaching contents of Advanced Mathematics are divided into 8 modules: the limit of the univariate function, the differential of the univariate function, the integral of the univariate function, the differential equation, the analytic geometry of the space, the differential of the multivariate function, and the integral of the multivariate function. And each of the eight modules is subdivided into knowledge points.

Then the questionnaires are distributed to different departments and majors, and teachers instructed to fill out the questionnaires. 
Based on results of the survey, teaching contents are selected into categories of "preliminary knowledge module, basic knowledge module, advanced knowledge module and applied knowledge module".

\section{Selection of Teaching Content and Syllabus Formulation}

The Syllabus Formulation Mainly Observes the "Horizontal Classification, Vertical Stratification" Principle

Horizontal classification means classifying knowledge points on college or major level. Vertical stratification means classifying teaching contents and goals on student level.

After the integration and optimization of teaching contents, teaching syllabus is formulated under two items: Science \& Engineering, Economics \& Management.

\section{Selection of Teaching Content}

Selection of teaching contents is based on the ready-made modules. For example, in the advanced knowledge module, students majoring in Economics \& Management or Accounting will study the application of Economic Function, Derivative and Integral in Economics; students of Mechanical and Vehicular Engineering school will study contents like Space Analytic Geometry; and students of Electrical and Information Engineering school will study Fourier Transform of Series, Curve and Surface Integral, etc..

\section{Hierarchical Classification of Teaching}

The students take part in a placement test as they enter the university and the results of the test decide which knowledge points they will learn in each module. For example, students with weak mathematics foundation should strengthen their study in preliminary knowledge module so as to lay a solid foundation for follow-up study and students of higher level will receive emphasis on advanced and applied knowledge modules while all students should master the major contents in basic knowledge module including Limit of one Variable Function, Differential and Derivative Operation.

\section{Selection of Teaching Methods}

Different from the traditional standardized "definition - theorem - example - exercises" teaching process, the new mode emphasizes cultivating students' ability to find, analyze and solve problems through specific-to-general method. To arouse students' interest in learning and develop their creativity, this mode combines a variety of teaching methods such as case teaching, heuristic teaching, research teaching, exploratory teaching and so on.

\section{Changes in Assessment Methods}

In the higher education system, learning assessment is a way to test what and how students have learned. The new mode includes both procedural and target assessment. Process assessment is reflected in usual performance while target assessment in results of final exam. The final exam also made a reform, testing students' ability to apply knowledge as well as their master of basic theory, knowledge and skills.

\section{Funding}

This research was supported by the Teaching reform in Jiangxi Province of china[grant number JXJG-16-27-4].

\section{References}

[1] YANG Hong-lin, DING Zhan-wen, TIAN Li-xin, Some Thoughts on Teaching Reform of Higher Mathematics Course[J] Journal of Mathematics Education 02(2004)57-59.

[2] David P. Wilson. Mathematics is applied by everyone except applied mathematicians[J] . Applied Mathematics Letters .5( 2008)636-637.

[3] Z .Zhu. On Teaching Reform and Curriculum System of Higher Mathematics [J] Technique \& Education.5(2007)41-47.

[4] R.J. Ong, J.T. Teaching Reform and Practice of Higher Mathematics in Applied Institutes [J] Education Exploration.6(2003) 42-43 
[5] Linyuan Fan. Study on Teaching Reform of Higher Mathematics in Economics and Management Specialty [J] 2017 International Conference on Sports, Arts, Education and Management Engineering (SAEME 2017) 